\title{
Osteochondroma occurring in a sesmoid bone of the thumb
}

\author{
Stoneham $\mathrm{A}^{\mathbf{1}^{*}}$, Logan $\mathrm{K}^{1}$ and Gheorgiu $\mathrm{D}^{2}$ \\ ${ }^{1}$ Orthopaedic Registrar, Wessex Deanery \\ ${ }^{2}$ Orthopaedic Consultant, St. Mary's Newport
}

\begin{abstract}
Case: We present the case of an osteochondroma occurring in a sesmoid bone of the thumb. A 59 year old gentleman presented with a slowly growing lesion on the volar aspect of his right thumb at the level of the interphalangeal joint. The lesion was excised and a histological diagnosis of osteochondroma was made. He made a good recovery with complete resolution of symptoms.
\end{abstract}

Conclusion: This is an exceedingly rare finding but potentially a very significant one. Tumours like this can cause pain, interfere with work or recreational activities, and (rarely) transform into malignant tumours.

\section{Introduction}

Chondromas are benign tumours, arising from aberrant physeal cartilage [1]. They occur within bone - either within the medullary cavity (enchondromas) or sub-periosteally (osteochondromas) - or within soft tissues such as tendon sheaths.

They most commonly occur in the hand, less often in the feet, and occasionally in long bones such as the femur or humerus [2]. They are the commonest benign tumour of the hand but because they are normally painless they may be under reported. They can cause swelling, pathological fractures or secondary compression of adjacent neurovascular structures [3] if allowed to progress. Malignant transformation is rare [4].

Tumours occurring within the seamoid bones are exceedingly rare and to our knowledge there has been only one prior documented case of thumb sesamoid chondroma [5].

\section{Case Report}

A 59-year old right hand dominant patient was referred to the orthopaedic department of a District General Hospital with a lesion on the volar aspect of his left thumb at the level of the interphalangeal joint (IPJ). The Patient had first noticed the lesion ten years earlier after sustaining a superficial burn to the area. The lesion subsequently increased in size and started causing symptoms of pain and reduced range of movement in the IPJ, which interfered with his work and activities of daily living and work. The patient had no other relevant personal or family history.

On examination the lesion was visible in the volar crease of the IPJ of the right thumb. It measured approximately one centimetre in diameter (Figures 1 and 2). The overlying skin was stretched but healthy and no neurovascular disruption was elicited. There was a normal range of flexion and extension.

AP and lateral radiographs showed an extracortical lesion overlying the IPJ (Figures 3 and 4). The lesion was well corticated with a central area of lysis, displaying heterogeneity of the matrix.
The lesion was excised under local anaesthetic and a finger tourniquet (Figure 5). A Brunner incision on the volar aspect of the thumb was utilised with careful soft tissue dissection, and the lesion excised in its entirety with the widest possible margin. Haemostasis with bipolar diathermy was performed and the skin was closed with directly with interrupted 4/0 Ethilon sutures.

Macroscopic pathological analysis showed a pale, firm, calcified lesion measuring 15 millimetres in its broadest diameter (Figure 6). Histological analysis revealed a nodular chondromatous neoplastic lesion composed of slightly irregular nests and nodular clusters of chondrocytes set within hyaline cartilaginous matrix. No mitotic figures were seen. There were small well-defined areas of necrosis and focal mucinous degeneration. No malignant features were noted. Microscopic appearances were those of a osteochondroma.

The patient was followed up post-operatively until complete wound healing and full resolution of symptoms.

\section{Discussion}

Sesamoid bones of the fingers and thumbs are situated in the volar plates [6] and thought to intracapsular structures [7]. Their role is to act as pulleys, as well as to protect tendons from excessive wear [6]. Chondromas of the sesamoid bones are extremely uncommon. There is in fact only one reported case of such a lesion affecting the sesamoid of the thumb [5]. There is one case of an aneurysmal bone cyst of the sesamoid bone of the index finger [8], but none of chondromas affecting the sesamoid bones of the fingers. There is also one report of a giant cell lesion in the thumb sesamoid [9]. Sesamoid bone lesions are known to occur as a result of trauma [6], however there is no documented association with burns. They can be excised for diagnosis

${ }^{\star}$ Correspondence to: Stoneham A, Orthopaedic Registrar, Wessex Deanery, UK, E-mail: adamstoneham@gmail.com

Received: March 28, 2018; Accepted: April 11, 2018; Published: April 14, 2018 


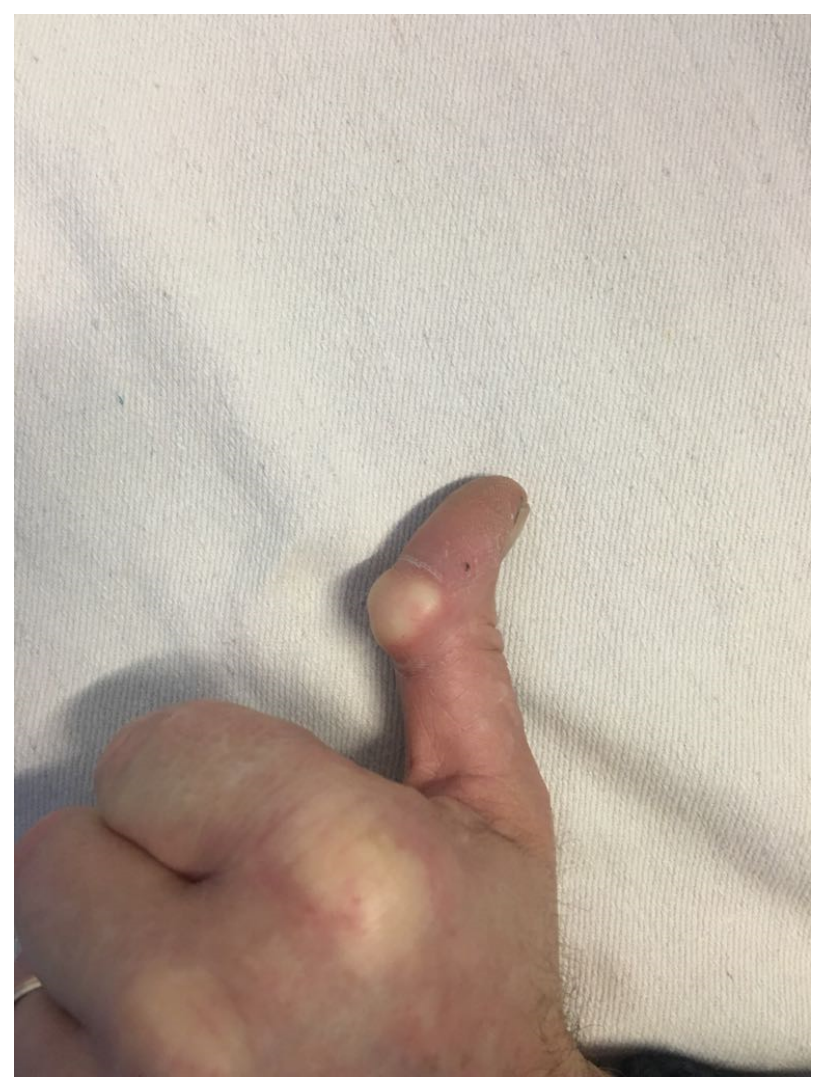

Figure 1. Pre-operative appearance of lesion on the volar aspect of the right thumb.

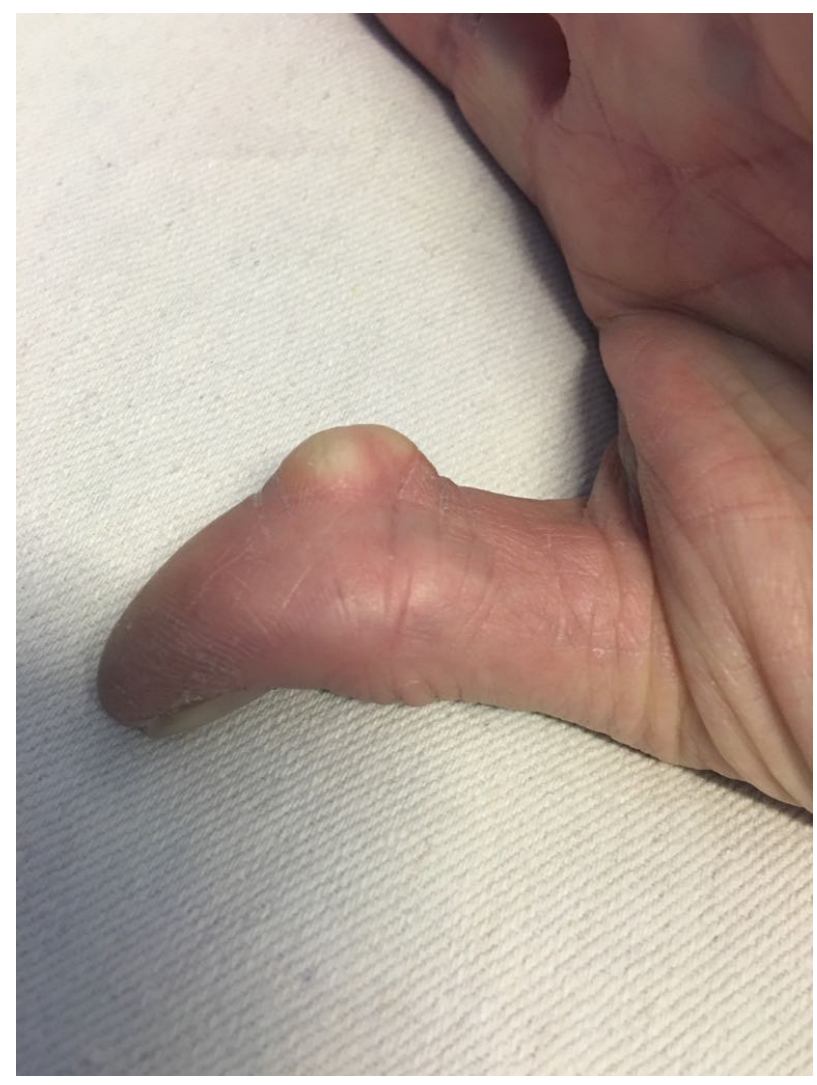

Figure 2. Pre-operative appearance of lesion on the volar aspect of the right thumb.

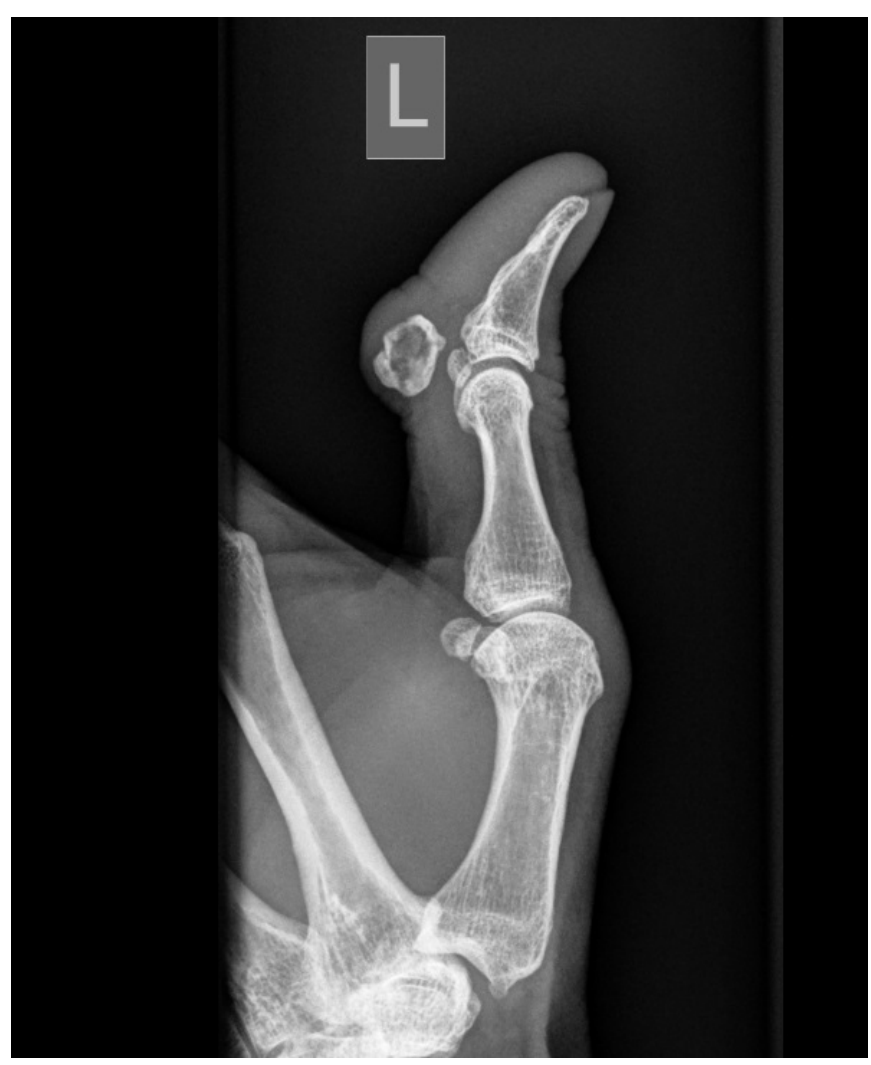

Figure 3. Lateral radiograph showing irregular, corticated lesion volar to the interphalangeal joint of the left thumb.

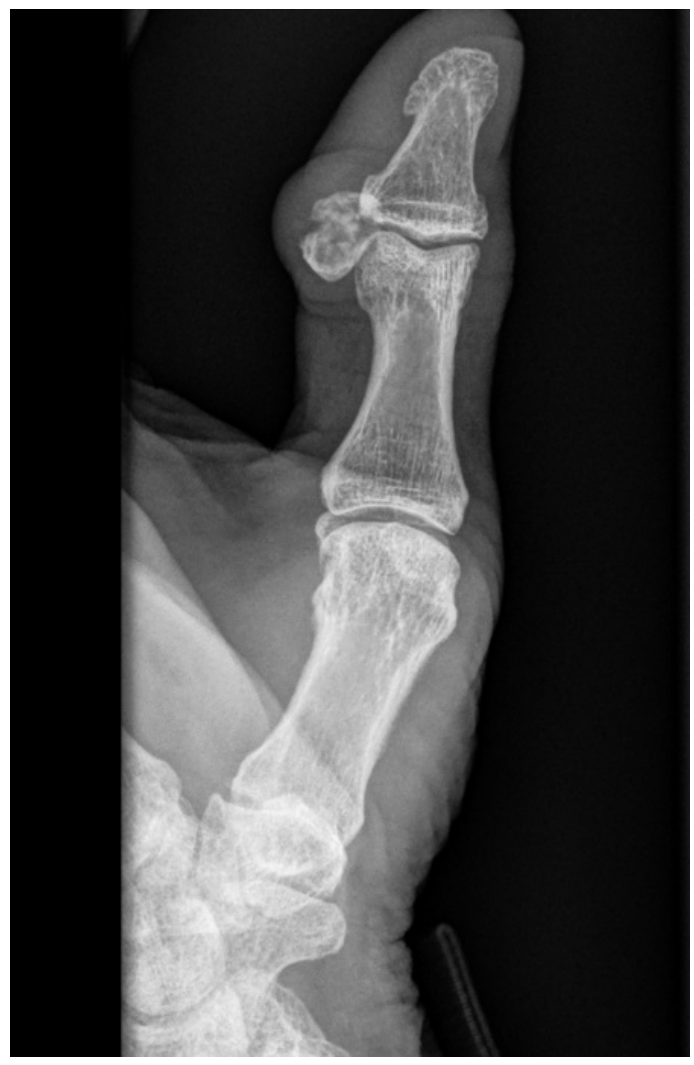

Figure 4. Oblique radiograph demonstrating the bony lesion with associated soft tissue swelling. 


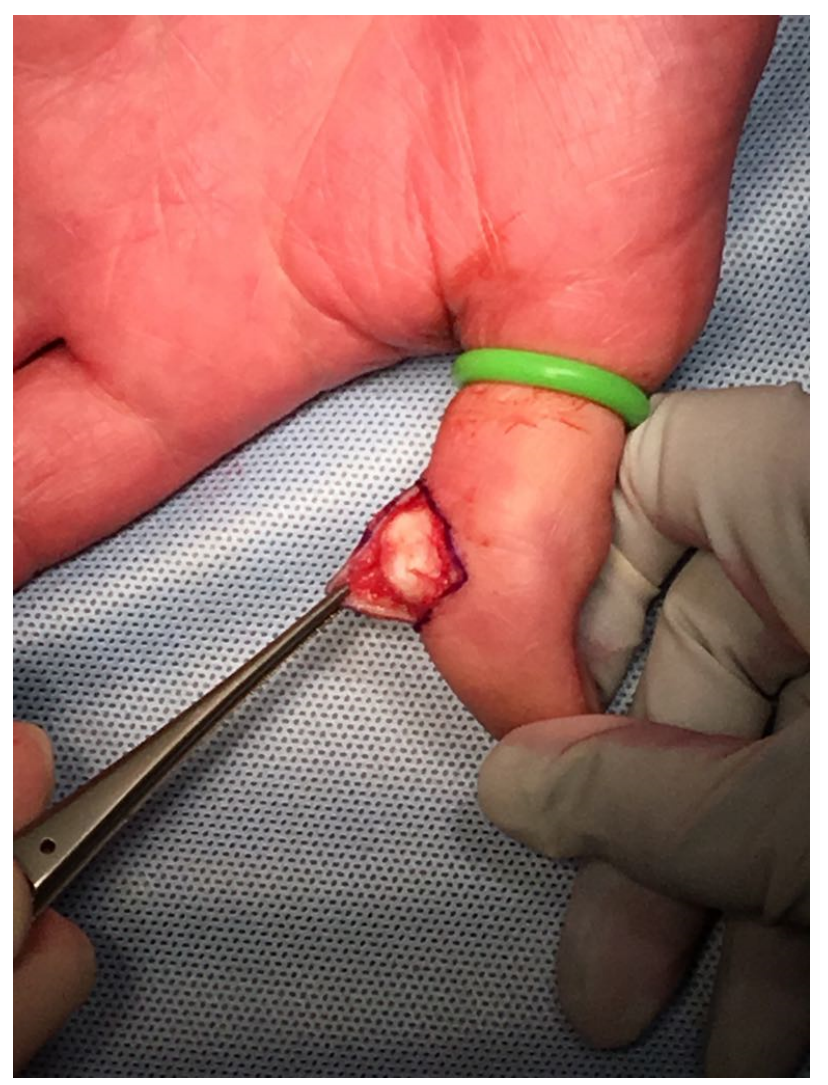

Figure 5. Intra-operative image showing dissection around the lesion under local anaesthetic and tourniquet.

and symptom relief. Chondromas have the potential to transform into chondrosarcoma, however this is a very rare event [10].

\section{Statement of informed consent}

The patient has given consent for this case (including images) to be used for educational purposes, and this is documented in his clinical notes.

\section{References}

1. Tang C, Chan M, Fok M, Fung B (2015) Current management of hand enchondroma: a review. Hand Surg 20: 191-195. [Crossref]

2. Milgram JW (1983) The origins of osteochondroms and enchondromas. A histopathologic Study. Clin Orthop Relat Res 174: 264-284. [Crossref]

3. Hsu CS, Hentz VR, Yao J (2007) Tumours of the hand. Lancet Oncol 8: 157-166. [Crossref]

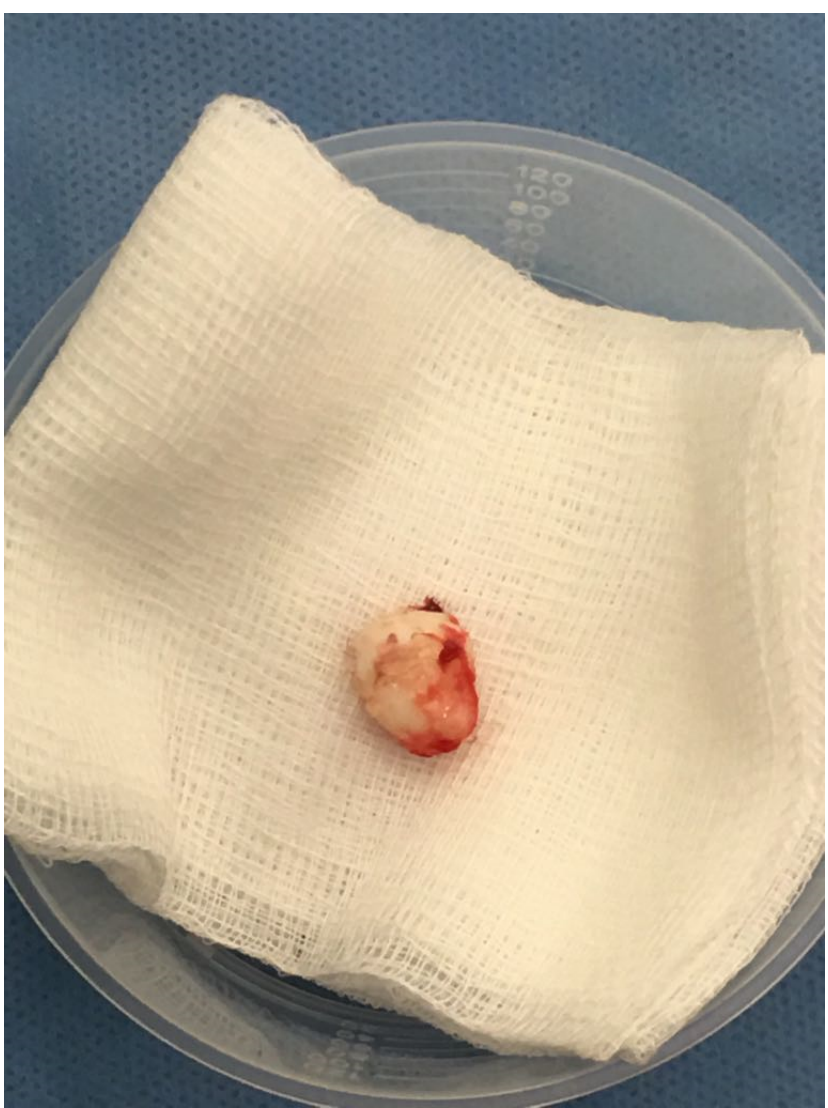

Figure 6. Gross macroscopic appearance of the dissected lesion.

4. Athanasian EA (1999) Bone and soft tissue tumors. DP Green, RN Hotchkiss, WC Pederson (Eds.), Green's operative hand surgery (4th edn.) Churchill Livingstone $2222-2253$

5. Louaste J, Amhajji L, Eddine EC, Rachid K (2008) Chondroma in a sesamoid bone of the thumb: case report. J Hand Surg Am 33: 1378-1379. [Crossref]

6. Lang CJ, Lourie GM (1999) Sesamoiditis of the index finger presenting as acute suppurative flexor tenosynovitis. J Hand Surg Am 24: 1327-1330. [Crossref]

7. Wood VE (1984) The sesamoid bones of the hand and their pathology. J Hand Surg $\operatorname{Br}$ 9: 261-264. [Crossref]

8. Havulinna J, Parkkinen J, Laitinen M (2005) Aneurysmal bone cyst of the index sesamoid. J Hand Surg Am 30: 1091-1093. [Crossref]

9. Clarke EP, Pritchett JW (1998) Giant-cell lesion in a sesamoid bone of the thumb. $J$ Hand Surg Br 23: 279-280. [Crossref]

10. Sridhar H, Vijaya M, Clement W, Srinivas C (2014) Chondrosarcoma arising in an enchondroma of the metacarpal bone - a case report. J Clin Diagn Res 8: 142-143. [Crossref]

Copyright: $@ 2018$ Stoneham A. This is an open-access article distributed under the terms of the Creative Commons Attribution License, which permits unrestricted use, distribution, and reproduction in any medium, provided the original author and source are credited. 